\title{
O VIÉS DE CONFIRMAÇÃO NA TOMADA DE DECISÃO NO ÂMBITO DO PROCESSO PENAL BRASILEIRO: O INSTITUTO DO JUIZ DE GARANTIAS COMO INSTRUMENTO DE DESENVIESAMENTO.
}

Hélio Roberto Cabral de Oliveira ${ }^{*}$

\begin{abstract}
RESUMO
O presente estudo pretende abordar o Direito processual penal a partir de uma perspectiva interdisciplinar, apoiando-se nas descobertas recentes provenientes da psicologia cognitiva e da economia comportamental sobre a tomada de decisão e julgamento, especificamente no tocante à existência de heurísticas e vieses, especialmente o viés de confirmação e sua influência no processo penal brasileiro. A partir daí, verificar-se-á o funcionamento do instituto do juiz de garantias e sua possível utilização como instrumento de desenviesamento da sentença penal, como forma de promover maior imparcialidade no julgamento.

Palavras-chave: Viés de Confirmação. Tomada de Decisão. Processo Penal. Juiz de Garantias. Desenviesamento.
\end{abstract}

\section{THE CONFIRMATION BIAS IN DECISION-MAKING IN THE CONTEXT OF THE BRAZILIAN CRIMINAL PROCEDURE: THE INSTITUTE OF THE GUARANTEES JUDGE AS A DEBIASING INSTRUMENT.}

\begin{abstract}
The present study intends to approach criminal procedural law from an interdisciplinary perspective, based on recent discoveries from cognitive psychology and behavioral economics about decision-making and judgment, specifically with regard to the existence of heuristics and biases. The focus will be the confirmation bias and its influence in Brazilian criminal procedure. Thereafter, the functioning of the guarantees judge institute and its possible use as an instrument for the debiasing of criminal sentence are verified, especially if it proves to be a useful and necessary instrument to provide greater impartiality to the judgment.

Keywords: Confirmation bias. Decision-making. Criminal proceeding. Guarantees Judge. Debiasing.
\end{abstract}

\section{INTRODUÇÃO}

O modo pelo qual o jurista analisa, interpreta e aplica a norma tem usualmente passado ao largo do estudo tradicional do Direito, que ainda se atém à análise do fenômeno jurídico com foco na norma e sua relação com o ordenamento. Ainda tem sido ignorada, pela doutrina e pela jurisprudência majoritárias, a questão da tomada de decisão e julgamento realizada pelo aplicador do Direito.

Na prática forense, pouca atenção tem sido dada à formação interdisciplinar dos

\footnotetext{
* Mestrando em Direito pela UFC. Defensor Público Federal. Endereço eletrônico heliocabrall1@gmail.com. ORCID https://orcid.org/0000-0001-7369-6078.
} 
profissionais do Direito, ignorando-se os mais recentes conhecimentos advindos das ciências cognitivas, ${ }^{1}$ como os temas relacionados à cognição, à emoção e ao inconsciente em relação à tomada de decisão jurídica.

Com base especialmente na psicologia cognitiva e na economia comportamental, tem-se questionado a racionalidade dos juristas e a imparcialidade dos julgadores, bem como tem-se considerado a influência das emoções, da intuição e dos chamados vieses cognitivos na interpretação jurídica.

A partir de tais discussões, será considerada a edição da recente Lei 13.964, de 24 de dezembro de 2019 (conhecida como "Pacote Anticrime"), que inaugurou o instituto do juízo de garantias no âmbito do processo penal brasileiro, ao introduzir no Código de Processo Penal pátrio os artigos $3^{\circ}$-A a $3^{\circ}$-F. Por meio desta inovação legal, em suma, cria-se a figura de um juiz específico para o controle de legalidade da investigação e a garantia dos direitos do investigado, cuja competência se encerra com a decisão de recebimento ou não da denúncia. A partir daí, inicia-se a competência de um segundo magistrado, o juiz da causa, alheio à fase investigatória. Parte da doutrina pátria, há tempos, com base em estudos de Direito comparado, vinha invocado a necessidade da criação de tal instituto no processo penal brasileiro, como forma de evitar a contaminação subjetiva do julgador que realizará a instrução e proferirá a sentença e, assim, trazer maior imparcialidade e, consequentemente, justiça ao julgamento.

Não obstante, ainda antes da entrada em vigor da Lei 13.964/19 (que ocorreria em 23/01/2020), o Ministro do Supremo Tribunal Federal Luiz Fux, na condição de relator da ADI 6.299, decidiu liminarmente em 22/01/2020, ad referendum do plenário, por suspender a eficácia de diversos de seus dispositivos legais, incluindo-se aí aqueles referentes ao instituto do juiz de garantias (artigos $3^{\circ}$-A a $3^{\circ}$-F do CPP), impedindo sua aplicação (BRASIL, STF, 2020).

O voto do ministro relator, ao fundamentar a plausibilidade de inconstitucionalidade material dos referidos dispositivos da referida lei que regulam o juiz de garantia e a necessidade de sua imediata suspensão ad cautelam, apresentou inicialmente argumentos de ordem prática, acerca da insuficiência de prazo para a implementação do novo instituto pelos

\footnotetext{
${ }^{1}$ No presente trabalho, utilizar-se-á a expressão "ciências cognitivas" para se referir, de forma genérica, ao conjunto de disciplinas que estudam a mente, o cérebro humano e o raciocínio, incluindo aí a neurociência, a psicologia e a economia comportamental.
} 
tribunais brasileiros, e outras questões, tal como a necessidade de um maior aprofundamento na análise de Direito Comparado (cf. sobre tal questionamento, cf. OLIVEIRA, 2020). Para além disso, no que interessa à presente pesquisa, o Min. Luiz Fux expressamente estatuiu que, embora reconheça a existência de estudos comportamentais que apontam que seres humanos desenvolvam vieses em seus processos decisórios, isso não poderia ser automaticamente aplicado no sistema de justiça criminal, sob pena de criar uma presunção generalizada de que qualquer juiz criminal do país teria tendências que favoreçam a acusação. Ademais, ainda entendeu o ministro relator que não se inferia que o instituto do juiz de garantias seria a estratégia institucional mais eficiente para minimizar eventuais vieses cognitivos.

Diante do exposto, a partir do último argumento mencionado da decisão acima, o presente trabalho, com base nos recentes achados da psicologia cognitiva e da economia comportamental, abordará o conceito de viés cognitivo, sua possível ocorrência em decisões no âmbito do processo penal e a viabilidade de o instituto do juiz de garantias servir como instrumento apto a evitá-lo ou reduzi-lo.

Para tanto, será utilizada, como metodologia, pesquisa do tipo bibliográfica, por meio da análise de livros, artigos e estudos empíricos, bem como documentos brasileiros, da legislação e da jurisprudência nacionais.

\section{A LACUNA SOBRE A ANÁliSE dO JULGAMENTO E DA TOMADA DA DECISÃO JURÍDICA}

No Brasil, o operador do Direito, em regra, ainda é tratado como uma categoria altamente racional, capaz de tomar sempre a melhor decisão em face do domínio dos fatos e do Direito, tratando-se de uma visão que reduz a complexidade do mundo para dar conta das atividades do dia a dia forense (NOJIRI, 2021, p. 59; ROSA, FELIX, 2019, p. 6). Em tal abstração, o ator jurídico, individual e concretamente considerado, acaba sendo visto como alguém que tem acesso a informação completa, ou pelo menos a necessária, tem tempo suficiente para reflexão, faz uma avaliação correta das circunstâncias fáticas e jurídicas e tem um propósito adequado à ordem jurídica. Em regra, tal concepção não condiz com a realidade prática (WOJCIECHOWSKI, ROSA, 2021, p. 13).

Em que pese, na prática, seja admitido que a tomada de decisão, em temas moralmente carregados ou juridicamente complexos, sofra influência de elementos subjetivos do jurista ou de fatores circunstanciais, pouco se diz porque ou como isso acontece (HORTA, 
2019, p. 85/86). A atenção dos estudos na Ciência do Direito parece ainda se dirigir sobretudo à norma e ao ordenamento jurídico, pouco avaliando o contexto subjetivo do operador do Direito quando da tomada de decisão. Atualmente, ainda se verifica uma visão da doutrina pátria essencialmente analítica, no sentido de realizar uma dissecção sistemática-conceitual do Direito vigente (sobre o conceito de dimensão analítica do Direito, cf. ALEXY, 2008, p. $33 / 34)$.

Entretanto, estudos interdisciplinares, sobretudo baseados em experimentos empíricos, tem apontado que a racionalidade do ser humano é limitada e que ignorar isso no âmbito da prática forense pode resultar em injustiças concretas, ${ }^{2}$ de forma que a abordagem do Direito não pode se pautar "numa visão da racionalidade de séculos atrás, como se a Psicologia, a Biologia e as Neurociências não tivessem avançado a passos largos nas últimas décadas" (HORTA, 2019, p. 86).

Como será analisado no próximo tópico, a psicologia cognitiva e a economia comportamental têm desenvolvido uma concepção mais real da racionalidade humana, abordando as suas naturais limitações, às quais o aplicador do Direito está vinculado. Tais conhecimentos são essenciais para que as instituições jurídicas possam ser analisadas a partir de uma perspectiva mais realista e menos ideal, evitando que injustiças sejam perpetuadas.

A Ciência Jurídica precisa, então, superar a visão que ainda tem do operador do Direito, em geral, e do julgador, em especial, como seres altamente racionais e passar a considerar a limitação da racionalidade humana quando da tomada da decisão jurídica, de modo a ponderar que questões relacionadas à cognição, à emoção e ao inconsciente inevitavelmente influenciarão na prática jurídica.

\section{DESENVOLVIMENTO DA TEORIA DO JULGAMENTO E TOMADA DE DECISÃO NO ÂMBITO DAS CIÊNCIAS COGNITIVAS}

De há muito tempo, estudos principalmente no âmbito da Economia e da Psicologia, a partir de experimentos empíricos, têm apontado que as pessoas, mesmo em situações relativamente simples e não se encontrando afetadas por emoções, como medo ou ódio, podem decidir fugindo de um padrão esperado de racionalidade, incidindo em erros sistemáticos de opinião ou análise estatística com pouca acurácia.

\footnotetext{
${ }^{2}$ Cf. o estudo pioneiro de SUNSTEIN; JOLLS e THALER, 1998 e, no Brasil, por todos, HORTA, 2019, e o farto levantamento de bibliografia nacional sobre o tema indicado em sua nota de rodapé n. 1.
} 
Herbert Simon, economista norte-americano, em meados da década de 1950, foi um dos pioneiros em questionar, de forma incisiva, a concepção, até então dominante e oriunda da economia neoclássica, de homem racional, o chamado homo economicus (SIMON, 1955). Em seus estudos, foi apontado que o ser humano recebe informações limitadas, muitas vezes faz avaliações pouco eficazes e tende a não perceber sua própria ignorância. Simon sustenta que, para lidar com a realidade, as pessoas a simplificam, o que pode gerar distorções (MYERS, 2014, p. 111).

Os estudos de Simon capturam o porquê do processamento incompleto e subjetivo de informação realiza um papel crítico na tomada de decisão, ao levar em consideração ideologias, percepções subjetivas da realidade e trazer à tona a complexidade e a incompletude das informações obtidas, além do esforço, muitas vezes desastroso, em decifrálas (NORTH, 1990, p. 23). Com base nisso, Simon estabeleceu o conceito de "racionalidade limitada".

Na década de 1970, o psicólogo Daniel Kahneman e o estatístico Amos Tversky apresentaram os trabalhos "Julgamento sob incerteza: Heurísticas e Vieses" e "Teoria da Perspectiva: uma análise da decisão sob risco" (tradução livre), em que eles documentaram erros sistemáticos na opinião de pessoas normais e localizaram esses erros no processo cognitivo. Os autores inferiram que tais erros não seriam um desvirtuamento do pensamento pela emoção, mas um desdobramento da racionalidade limitada (RICHARD, 2015, p. 33-35). Foi reconhecido que as pessoas recorrentemente incidiriam em erro, o que seria uma forma disfuncional de processar informação e afetaria o raciocínio lógico-abstrato, mas aconteceria de forma previsível em pessoas de todos os países e culturas (COSTA, 2016, p. 47).

Surgiria daí o chamado programa das "heurísticas e vieses", o qual buscava compreender quais seriam as estratégias decisórias que empregariam atalhos cognitivos ("heurísticas"), de modo a resolver intuitiva e rapidamente problemas complexos. No entanto, muitas vezes esses atalhos resultariam em desvios sistemáticos ou inconsistências em relação aos parâmetros normativos esperados ("vieses") (HORTA, 2019, p. 89).

Os estudos de Daniel Kahneman e Amos Tversky são considerados os fundamentos da economia comportamental (KAHNEMAN, 2012, p. 19) e acabariam por influenciar diversos outros ramos do conhecimento, como a Psicologia, a Sociologia, a Ciência Política e o Direito, que passam, ou deveriam passar, a considerar as heurísticas e os vieses cognitivos (cognitive bias) como fatores relevantes no processo decisório. Entende-se que as heurísticas 
são ferramentas cognitivas, verdadeiros atalhos mentais, que proporcionam uma decisão rápida e geralmente eficiente, mas que podem sistematicamente (e não aleatoriamente) levar a erro, surgindo daí os vieses.

As descobertas apontadas não se propõem a atestar que o ser humano seria irracional ou que as heurísticas necessariamente seriam ruins e trariam prejuízos, tampouco diz-se que racionalidade limitada seria uma decorrência de pouca inteligência, dado que até mesmo pessoas muito inteligentes se submetem às falhas cognitivas (COSTA, 2018, 87). O propósito é admitir as heurísticas e vê-las como ferramentas, verdadeiros atalhos mentais, que proporcionam uma decisão rápida e geralmente eficiente, mas que podem sistematicamente (e não aleatoriamente) levar a erro, os vieses cognitivos (MYERS, 2014, p. 93).

\section{O VIÉS DE CONFIRMAÇÃO}

Estudos tem mostrado que a primeira impressão tem um peso desproporcional, gerando uma tendência de as pessoas filtrarem as informações que posteriormente recebem, de modo que, inconscientemente, buscam e supervalorizam as provas e os argumentos que confirmam sua própria posição inicial, além de ignorar ou não valorizar devidamente provas e argumentos que não respaldam sua posição, o que tem sido chamado de viés de confirmação (COSTA, 2018, p. 114-115).

Um dos primeiros estudos empíricos sobre o viés de confirmação, embora não tenha utilizado tal expressão, foi desenvolvido pelo psicólogo P. C. Wason e se chamou "Sobre a falha em eliminar hipóteses em uma tarefa conceitual" (tradução livre, WASON, 1960). O propósito do estudo era conferir se as pessoas testariam hipóteses da mesma forma que cientistas em regra fazem, ou seja, falseando-as.

No experimento, Wason reuniu um grupo de estudantes universitários, lhes apresentou uma simples sequência formada pelos números 2-4-6 e informou que haveria uma regra pautando a ordem dos números apresentados, a qual deveria ser descoberta pelos participantes por meio de quantas tentativas fossem necessárias. Assim, cada aluno, individualmente, deveria anotar em um papel outras sequências de 3 números, juntamente com uma hipótese sobre a regra, e apresentar para o organizador para conferir se a sequência criada se adequava à regra estabelecida, nada sendo dito, a princípio, sobre a hipótese levantada pelo aluno. Após reunir o número de sequências testadas que entendesse suficiente e acreditasse ter descoberto o teor da regra, o participante deveria confirmar com o 
organizador se sua hipótese corresponderia à regra existente. A ideia era simular um problema científico em miniatura, no qual as evidências precisariam ser sistematicamente testadas para refutar ou suportar a hipótese (WASON, 1960, p. 139).

$\mathrm{Na}$ maioria dos casos, no entanto, verificou-se que os participantes tendiam a testar sequências que eram compatíveis com a hipótese inicialmente apresentada, de modo tal que as sequências em seguida apresentadas tendiam a confirmar a hipótese inicial que eles tinham em mente. Wason percebeu que a maioria dos participantes não testava sequências que não correspondiam à hipótese sobre a regra que tinham em mente, mas apenas sequências que confirmavam tal hipótese. Os resultados então apontaram que, em geral, apenas poucos pessoas espontaneamente testam suas próprias crenças tentando falseá-las, de modo que evidências confirmadoras isoladas compelem-nas a confirmar o que já acreditavam (WASON, 1960, p. 139).

A partir do estudo de Wason, a controvérsia sobre uma possível tendência humana de confirmação de hipóteses passou a ser objeto de estudo da Psicologia, superando o confinamento no âmbito da Filosofia, incluindo aí a Filosofia da Ciência (OSWALD; GROSJEAN, 2005, p. 81).

Vários estudos empíricos, no âmbito da Psicologia, foram apresentados posteriormente, desenvolvendo a ideia da existência de uma viés de confirmação inerente ao raciocínio humano (cf., p. ex., LORD; ROSS e LEPPER, 1979). Ainda que haja críticas à intensidade e frequência com que o viés de confirmação possa ocorrer (MERCIER, 2017), tanto filósofos como psicólogos tem observado que pessoas acham mais fácil acreditar em proposições que elas gostariam de ser verdade, dado que há uma tendência de darem tratamento preferencial a pensamentos agradáveis em relação àqueles desagradáveis, surgindo daí o viés (NICKERSON, 1998, p. 197). Para muitos, é um dos mais robustos e inquestionáveis vieses na literatura da Psicologia Cognitiva e Social (HAIDT, 2013, p. 873).

Os estudos têm apontado que há uma natural tendência de as pessoas analisarem as informações a partir de filtros, influenciados por preferências, ideologias e circunstâncias. Não se trata de uma tentativa intencional de distorcer dados, mas de algo inerente ao próprio processo decisório e ao modo como as pessoas, a partir de seus próprios contextos, direcionam a percepção e a atenção.

Em resumo, pode-se dizer que o viés de confirmação consiste em favorecer de forma involuntária informações congruentes com as expectativas em detrimento de informações 
incongruentes com elas (OSWALD; GROSJEAN, 2005, p. 93). Além disso, não há busca por contra-argumentos de forma efetiva, de modo que, quando uma informação contraditória é identificada, a ela é dada pouca importância. (NICKERSON, 1998, p. 175)

O viés de confirmação pode ocorrer de diferentes formas: (1) memórias congruentes com a hipótese são mais provavelmente acessadas que memórias incongruentes com ela; (2) um peso indevido é dado para a importância de informação congruente com a hipótese, possivelmente porque da concentração na hipótese e na negligência com explicações alternativas; (3) as fontes com informação que possam rejeitar a hipótese são evitadas, desde que a pessoa saiba, a priori, a opinião da fonte (OSWALD; GROSJEAN, 2005, p. 93).

O reconhecimento da existência do viés de confirmação e de sua possível recorrência no processo decisório é de suma importância para que possa ser ativado um alerta, de modo que formas para evitá-lo ou reduzi-lo possam ser pensadas (NICKERSON, 1998, p. 211).

\section{O VIÉS DE CONFIRMAÇÃO NO PROCESSO PENAL}

Ao longo de sua história, o Direito Processual Penal brasileiro foi se desenvolvendo de modo a delimitar a atuação dos atores jurídicos que participam da persecução penal, sendo criada e aprimorada a separação das funções de investigar, acusar, defender, julgar e apreciar recursos. Em regra, tem-se uma clara delimitação formal do papel de cada instituição, de modo que haja maior eficiência no cumprimento do respectivo dever legal, o devido controle e maior imparcialidade, com o fim último de proporcionar um julgamento justo.

A separação das funções e a questão da imparcialidade dos julgamentos têm sido objeto de tradicionais discussões jurídico-filosóficas, sobretudo em relação à natureza do sistema processual penal brasileiro, se acusatório, inquisitivo ou misto. Poucas, contudo, tem sido as contribuições interdisciplinares do tema no Brasil sob a perspectiva das ciências cognitivas.

Ricardo Lins Horta expõe a necessidade de estabelecer uma visão do Direito em diálogo com as ciências comportamentais, até como forma de superação do conceito ainda dominante de racionalidade e melhor observar os limites das instituições: se é sabido que o cérebro é construído em torno de atalhos cognitivos, em vez de funcionar conforme parâmetros normativos, é preciso ajustar a visão que se tem das limitações dos tomadores de decisões humanos (HORTA, 2019, p. 112). 
$\mathrm{Na}$ doutrina estrangeira, sobretudo a norte-americana, tem sido observada a ocorrência de erros dos atores jurídicos decorrentes das mais variadas causas ligadas ao processo cognitivo, tal como análise falha sobre depoimentos testemunhais, realização defeituosa de identificação pessoal, falsas confissões, perícia forense enviesada, visão em túnel, julgamentos afetados por vieses, etc. (FINDLEY e SCOTT, 2006, p. 292).

Especificamente sobre a ocorrência de julgamentos enviesados no âmbito do processo penal, foi elaborado estudo pelo jurista alemão Bernd Schünemann (2012), onde foi feito experimento empírico com a participação de 58 juízes e membros do Ministério Público alemães. Partindo da premissa de que o julgador deve ser um terceiro não interessado e imparcial, foi investigado o funcionamento do processo penal alemão, que, segundo o autor, segue rito processual semelhante ao procedimento ordinário do processo penal brasileiro: finda a investigação, o Ministério Público formula a acusação e o juiz, que atuou no curso do inquérito, com base nas informações aí colhidas, decide se há verossimilhança no pleito e se recebe ou não a denúncia. Recebida a denúncia, o inquérito passa a integrar os autos. No curso da instrução, concentrada na audiência de instrução e julgamento, o juiz, tal qual as partes, exerce atividade instrutória, podendo ter papel ativo na produção de provas para, ao final, proferir sentença.

O propósito do experimento foi verificar se o julgador, por ter contato com o inquérito durante a investigação e decidir sobre o recebimento da denúncia, seria influenciado por esse inquérito quando da realização da instrução processual, fazendo mais perguntas às testemunhas e ao acusado que respaldem a acusação, e, ao decidir o mérito da causa, se haveria uma tendência de condenar mais. Investigou-se assim se o magistrado, que já formou determinada concepção da pretensão acusatória ao receber a denúncia, teria uma tendência confirmatória, supervalorizando informações que confirmem o inquérito e a decisão de recebimento da denúncia, bem como desvalorizando as demais que não confirmassem a ideia já formada (SCHÜNEMANN, 2012).

Foram então levantadas as seguintes hipóteses: 1. ${ }^{a}$ Hipótese - O magistrado condena mais frequentemente quando, antes da audiência de instrução e julgamento, possui conhecimento dos autos do inquérito do que quando não os conhece. Este fenômeno é reforçado pela possibilidade de inquirir os sujeitos da prova. 2. ${ }^{a}$ Hipótese - Na audiência de instrução e julgamento, o juiz comete mais erros na retenção das informações que não se conjugam com o teor do inquérito quando o conhece previamente do que quando não dispõe 
desse conhecimento. 3. ${ }^{a}$ Hipótese - Haverá uma redução no quantitativo de erros quando inexistir o conhecimento prévio do inquérito pelo magistrado. Esse percentual de erros será substancialmente minorado quando o magistrado puder inquirir pessoalmente os sujeitos da prova. 4. ${ }^{a}$ Hipótese - Haverá maior número de perguntas formuladas na audiência de instrução e julgamento para os sujeitos da prova quando o magistrado conhecer previamente o inquérito.

Para o experimento, foi formulado um caso fictício, a partir de um caso real, onde as provas eram contestáveis, de modo que, sem erro técnico, permitiriam que fosse proferida tanto uma sentença condenatória como uma absolutória. A audiência foi simulada por computador, permitindo que os participantes fizessem perguntas para testemunhas virtuais, que respondiam com base em um banco de respostas previamente formuladas, de forma que todos receberiam as mesmas respostas. Ao final, a pessoa deveria proferir uma sentença, condenatória ou absolutória, e, após, responder um questionário que serviria como teste de memória sobre as informações do caso.

Os participantes do experimento foram divididos em 4 grupos. O primeiro grupo era formado por participantes com acesso aos autos do inquérito e com possibilidade de atuação ativa na audiência de instrução e julgamento, com formulação de perguntas para as testemunhas virtuais. No segundo grupo, as pessoas tiveram acesso ao inquérito, mas foram impossibilitadas de inquirir as testemunhas. No terceiro grupo, não havia acesso ao inquérito, mas era dada a possibilidade de formular perguntas. O quarto e último grupo não tinha acesso ao inquérito e não tinha possibilidade de inquirir testemunhas.

As variáveis, então, eram o conhecimento dos autos do inquérito e a faculdade de inquirição pessoal das testemunhas na audiência de instrução e julgamento, que era simulada por meio de um computador, sendo ofertadas respostas idênticas a todos os participantes a partir de um banco de respostas.

Findo o experimento, verificou-se que todos os 17 juízes criminais que tiveram acesso ao inquérito condenaram o réu. Por outro lado, entre os juízes que não foram equipados com esta peça de informações houve divergência e, em tal subgrupo, 8 condenaram e 10 absolveram. O conhecimento dos autos do inquérito levou, sem exceções, os juízes a condenar o acusado. Esta tendência permaneceu mesmo diante de uma audiência de instrução e julgamento ambivalente, que poderia ter levado a uma absolvição.

Ademais, verificou-se que a maioria das perguntas foi formulada por aqueles que 
condenaram e tinham conhecimento do inquérito, enquanto o subgrupo que menos formulou perguntas foi constituído pelos que absolveram e não tiveram acesso ao inquérito. Este subgrupo, no entanto, apresentou maior nível de memorização, maior que o subgrupo que mais questionou, o qual foi o que se saiu pior no teste de memória. A partir disso, o estudo concluiu que a quantidade de perguntas não tem relação com a qualidade do processamento das informações, de modo que "a formulação de perguntas mais se aproxima de uma autoconfirmação da hipótese de partida do que de um aprimoramento na assimilação das informações" (SCHÜNEMANN, 2012).

Com tal experimento empírico, que aproximou-se ao máximo possível de um processo judicial real, todas as hipóteses levantadas foram confirmadas. O estudo concluiu no mesmo sentido que a literatura jurídica alemã já presumia por mera análise filosófica: o desacerto do papel do juiz na audiência de instrução e no julgamento, por ter conhecido previamente os autos do inquérito e decidido pelo recebimento da denúncia. Demonstrou-se que haveria uma tendência de o julgador confirmar sua decisão prévia (SCHÜNEMANN, 2012).

Estudo semelhante foi elaborado no Brasil por Ricardo Jacobsen Gloeckner (GLOECKNER, 2015, p. 263-286). Foram analisados 185 acórdãos do Tribunal de Justiça do Rio Grande do Sul, proferidos em sede de apelação e publicados entre 03/10/2012 e 31/12/2013, bem como as sentenças previamente proferidas. Os acórdãos foram obtidos por meio de busca no site do tribunal utilizando a expressão "prisão preventiva". O propósito do estudo era "confrontar os reflexos que a decretação da prisão processual acarretava para a decisão de mérito" (GLOECKNER, 2015, p. 269). Foi levantada a hipótese de que a prisão processual se constitui como um dos principais problemas para uma cognição ampla no processo penal, produzindo decisões enviesadas.

Foram desprezados acórdãos que não enfrentaram o mérito penal, tal como casos de declaração de nulidade processual, dosimetria da pena, processos do Tribunal do Júri e reforma de sentença que decretou absolvição sumária. O foco foi direcionado aos acórdãos condenatórios, absolutórios ou confirmatórios de condenação decretada na sentença, onde a prisão preventiva era enfrentada na discussão do mérito.

Depois da análise prévia, foram examinados 90 acórdãos, que atendiam aos critérios da pesquisa, e constatou-se que em todos eles houve a confirmação de uma decisão condenatória ou, então, a reforma da decisão absolutória de primeira instância, com a 
condenação do acusado em segundo grau (GLOECKNER, 2015, p. 274).

O resultado obtido no experimento foi no sentido de que "de forma direta ou indireta a prisão processual (como regra geral a prisão em flagrante) foi utilizada como elemento formador de convicção judicial em todos os casos”. Em cada acórdão analisado, em alguma instância ocorreu a menção à prisão processual como fundamento da decisão.

Em suas conclusões, assevera o autor que, quando o juiz, no curso da investigação, tem contato com uma versão unilateral dos fatos (dado que, em regra, a defesa não participa da reconstrução dos fatos no inquérito) e decide pela decretação da prisão preventiva, tal entendimento servirá como alicerce para as demais decisões, em razão de uma expectativa de consonância (GLOECKNER, 2015, p. 279). Ao fim, o autor apresenta as algumas propostas para reduzir o enviesamento, cabendo aqui destacar as sugestões no sentido que o magistrado que decreta uma prisão processual não pode decidir o mérito e que mecanismos de disfluência processuais devem ser introduzidos (como a segmentação do processo em fases, com os cuidados para se garantir que uma não invada a outra) no processo penal (GLOECKNER, 2015, p. 283).

Tais estudos empíricos, direcionados ao funcionamento da própria Justiça e à atuação dos atores jurídicos, em especial os julgadores, apontam para a ocorrência do viés de confirmação no âmbito do processo penal, tal como estudos psicológicos já vem há décadas o demonstrando na vida cotidiana. Ainda que se entenda que esses estudos não são definitivos e que seria necessário um maior aprofundamento, não há como se negar que eles trazem fortes evidências da constatação do viés de confirmação no processo penal, o que não pode ser desconsiderado, cabendo ao jurista interpretar a incerteza científica em favor da busca pela imparcialidade (COSTA, 2016, p. 88).

Assim, diferentemente do que constou na decisão do Ministro do STF Luiz Fux que suspendeu os dispositivos legais que inauguraram o instituto do juiz de garantias no processo penal brasileiro (BRASIL, STF, 2020), não se está a dizer que há uma presunção generalizada de que haveria uma tendência do julgador criminal em favorecer a acusação, mas sim apontar a possibilidade de ocorrer sistematicamente julgamentos enviesados, que pode inclusive favorecer absolvições indevidas e, ao fim, acaba prejudicando a própria ideia de imparcialidade do Poder Judiciário.

Nesse sentido, cabe observar que a atuação enviesada do magistrado, com um consequente posicionamento confirmatório e parcial, pode ocorrer para favorecer não só 
condenações injustas, mas também absolvições indevidas. Basta pensar no caso de uma possível tendência absolutória de um julgador que indeferiu medidas cautelares contra um denunciado e, ao analisar a denúncia, decretou a absolvição sumária ou entendeu pela falta de justa causa. Caso tal decisão venha a ser reformada pelo tribunal, em sede recursal, haveria a determinação de processamento do feito em primeira instância e posterior julgamento do mérito da ação. No modelo atual, o processo, ao voltar ao juízo a quo, seria recebido pelo mesmo magistrado que já teria formado previamente sua convicção sobre o caso. Ainda que venha a ser posteriormente influenciado pela instrução processual, haverá uma tendência a confirmar o entendimento já formado.

Necessário se faz então buscar instrumentos legais aptos a minimizar a possibilidade desse enviesamento. Neste contexto, cabe analisar se o instituto do juiz de garantias se mostra como uma alternativa viável para tanto.

\subsection{A PROMULGAÇÃO DO INSTITUTO DO JUIZ DE GARANTIA}

O instituto do juiz de garantias foi inaugurado no Código de Processo Penal brasileiro pela Lei 13.964, de 24 de dezembro de 2019 (conhecida como "Pacote Anticrime"), que introduziu os artigos $3^{\circ}$-B a $3^{\circ}$-F no referido código.

$\mathrm{O}$ anteprojeto da referida lei se baseou em grande parte no Projeto de Lei do Senado n. 156/09, de autoria do Senador José Sarney, posteriormente convertido no PL 8.045/10, atualmente em trâmite perante a Câmara dos Deputados, que por seu turno, se inspirou em diversos diplomas legais estrangeiros, como os Códigos de Processo Penal italiano e chileno (MAYA, 2020, p. 87). Em ambos, guardadas as especificidades de cada ordenamento jurídico, procedeu-se à especialização das funções do juiz que é chamado a intervir na investigação, como forma de diferenciar do juiz que assume a fase processual (SILVEIRA, 2009, p. 88-89).

O legislador pátrio buscou inspiração em modelos já consagrados na legislação estrangeira, onde reformas processuais penais buscaram efetivar o sistema acusatório e valorizar a imparcialidade do Poder Judiciário (SILVA, 2012, p. 63).

O escopo do instituto do juiz de garantias é então separar a atuação jurisdicional de primeira instância em duas fases distintas: a primeira concernente à investigação preliminar e a segunda referente à fase processual propriamente dita, que se inicia após o recebimento da denúncia ou queixa. 
No novo modelo legal, em cada uma das fases atuará um magistrado distinto, tratando-se de verdadeira competência funcional por fase do processo (LIMA, 2020, p. 114).

O juiz de garantias está encarregado de realizar o controle da legalidade da investigação, bem como decidir acerca de medidas que impliquem em restrições de direitos do investigado, tal como previsto no rol exemplificativo previsto no art. $3^{\circ}-\mathrm{B}$ do CPP. Não se tratando de um juiz instrutor, nos moldes do já abordado modelo europeu, não comandará a investigação, não lhe cabendo colher informações, determinar sua produção ou realizar diligências, tampouco será instado a decidir acerca de cada passo da autoridade policial, mas apenas nos casos previstos na lei processual, em especial quando houver reserva constitucional de jurisdição. É ele, portanto, “o guardião das regras do jogo e não senhor da investigação preliminar" (LIMA, 2020, p. 119).

Por sua vez, o juiz da causa (responsável pela instrução e julgamento) passa a atuar após o recebimento da denúncia ou queixa e decidirá as questões pendentes, mas não ficará vinculado às decisões proferidas pelo juiz das garantias (art. $3^{\circ}-\mathrm{C}, \S \S 1^{\circ}$ e $2^{\circ}$ do $\mathrm{CPP}$ ). Por outro lado, os autos da investigação (inquérito policial ou equivalente) não serão apensados aos autos do processo enviados ao juiz da instrução e julgamento, ressalvados os documentos relativos às provas não repetíveis, medidas de obtenção de provas ou de antecipação de provas, que deverão ser remetidos para apensamento em apartado (art. $3^{\circ}-\mathrm{C}, \S 3^{\circ}$, do $\mathrm{CPP}$ ).

No novo modelo processual "a competência do juiz das garantias abrange todas as infrações penais, exceto as de menor potencial ofensivo" (primeira parte do art. $3^{\circ}-\mathrm{C}$ do CPP), mas não há qualquer previsão de funcionamento em outra instância que não a primeira, seja em ações penais de competência originária dos tribunais, seja em grau recursal.

O regramento previsto nos artigos $3^{\circ}-\mathrm{B}$ até $3^{\circ}-\mathrm{F}$ do CPP propõe-se a conferir máxima eficácia às normas de direitos e garantias fundamentais, em especial ao direito de ser julgado por um juiz imparcial, o qual, embora não esteja expresso na Constituição Federal de 1988, decorre diretamente da garantia do devido processo legal e está expressamente previsto na Convenção Americana de Direitos Humanos (art. 8 , 1) (MAYA, 2020, p. 131).

Assim, com a própria reforma legislativa, parte da doutrina admite que o instituto do juiz de garantias é componente da estrutura acusatória do processo penal brasileiro, que foi 
legalmente consagrada com inserção do art. $3^{\circ}$-A no $\mathrm{CPP},{ }^{3}$ de forma tal que, sem o novo instituto, essa estrutura será inviável. Trata-se de repensar o sistema processual penal, não apenas pela imposição de funções diferenciadas (juiz de garantias e juiz de julgamento), mas pelo modo de funcionamento de todo o processo penal (ROSA, 2020, p. 344).

Seguindo tal entendimento, a literatura jurídica em geral, quando entende pelo desacerto do papel do juiz na audiência de instrução e julgamento em razão de sua contaminação subjetiva na fase investigatória e ao decidir pelo recebimento da denúncia, parte de uma perspectiva filosófica, mas não seria possível dizer que isso estaria comprovado metodologicamente, por falta de demonstração prática (SCHÜNEMANN, 2012).

Por tais motivos, a justificativa filosófica do instituto do juiz de garantia deve se aliar aos estudos empíricos expostos no presente trabalho, superando o campo meramente especulativo para adentrar em uma constatação prática. Diante de tais estudos, pode-se afirmar, de forma muito mais assertiva, a importância da criação de tal instituto no processo penal brasileiro, que pode ser apto a evitar a ocorrência do viés de confirmação e, consequentemente, promover uma maior imparcialidade do juiz da causa.

\subsection{O INSTITUTO DO JUIZ DE GARANTIA COMO INSTRUMENTO DE DESENVIESAMENTO}

Uma das técnicas possíveis para evitar o enviesamento é a criação de regras jurídicas ou institutos capazes de isolar o agente enviesado e substituí-lo por outro não enviesado (COSTA, 2016, p. 90). O isolamento significa restringir o domínio de decisão disponível para um primeiro indivíduo, de modo tal que um segundo indivíduo entraria em cena não afetado por um possível enviesamento (PI; PARISI e LUPPI, 2014, p. 150).

Seguindo tal lógica, por meio do instituto do juiz de garantias, isola-se o magistrado que instruirá e sentenciará a causa, protegendo-o de possível enviesamento decorrente de uma atuação no curso da investigação (COSTA, 2020). Durante o procedimento investigatório, cabe ao juiz de garantias analisar os elementos de informação aí formados, tanto para apreciar pedidos de medidas cautelares (pessoais ou reais), como para controlar a legalidade da própria investigação, além de, por fim, decidir pelo recebimento, ou não, da denúncia ou queixa. Com

\footnotetext{
3 “Art. $3^{\circ}$-A. O processo penal terá estrutura acusatória, vedadas a iniciativa do juiz na fase de investigação e a substituição da atuação probatória do órgão de acusação". Frise-se que tal dispositivo legal foi suspenso por decisão do Min. Luiz Fux, na ADI 6.099, de 22/01/2020, ainda que não tivesse qualquer pertinência com as razões de decidir, que estavam direcionadas especificamente contra o instituto do juiz de garantias.
} 
tal procedimento sendo processado perante o juiz de garantias, o juiz da causa, que sequer terá acesso aos autos do inquérito, fica resguardado de possível contaminação subjetiva pelos elementos de informação e decisões até então formados, evitando-se que incida em viés de confirmação.

Importante nesse ponto que o acesso ao inquérito por parte do magistrado do processo, em violação ao disposto no art. $3^{\circ}-\mathrm{C}, \S 3^{\circ}$, do CPP, implicaria em comprometimento ao seu isolamento e prejudicaria a divisão funcional estabelecida com o juiz de garantias, que apenas se prestaria a caracterizar uma falácia garantista (ROSA, 2020, p. 350).

A partir da perspectiva da psicologia cognitiva, o instituto do juiz de garantia revelase então como um instrumento legal que "impede que os vieses cognitivos contraídos pelo juiz no curso das investigações criminais sejam levados ao processo judicial" (COSTA, 2020). Trata-se, assim, de uma estratégia processual visando reforçar a imparcialidade do juiz da causa, ao evitar seu enviesamento, uma vez que não terá que se confrontar com decisões anteriores suas relacionadas à causa penal posta em juízo.

Se, comprovadamente, tal como já exposto, a partir de diversos estudos empíricos, as pessoas em geral, e o julgador em particular, tem uma tendência a confirmar suas próprias hipóteses, então trará maior imparcialidade um instrumento legal que se proponha a evitar que um mesmo magistrado, que decidiu a partir de uma versão unilateral dos fatos em um primeiro momento (fase de investigação, onde as informações são trazidas basicamente pelo órgão investigatório), tenha que rever e confrontar suas próprias decisões posteriormente (na fase processual, durante a instrução e julgamento, onde será garantido o contraditório e a ampla defesa).

\section{CONSIDERAÇÕES FINAIS}

O presente trabalho procurou se afastar de uma perspectiva estritamente analítica do Direito, o fazendo por meio de um estudo interdisciplinar com base empírica, com apoio na psicologia cognitiva e na economia comportamental, o qual acaba sendo mais realista, no sentido de levar em consideração o contexto subjetivo dos atores jurídicos quando decidem, já que não parte do entendimento de que eles seriam estritamente racionais. Considerou-se que as instituições jurídicas são construções humanas e, como tal, precisam admitir as limitações inerentes ao raciocínio humano para que possam ser criticamente analisadas e, assim, evitar, na medida do possível, que injustiças sejam perpetradas. 
Partindo da premissa de que a racionalidade humana é limitada, abordou-se diversos estudos empíricos que foram confirmando tal premissa não só no cotidiano das pessoas, como também no âmbito do processo penal.

Observou-se que a racionalidade humana é comprovadamente limitada, ficando clara a natural utilização de atalhos cognitivos (heurísticas), que, embora geralmente funcionem bem, podem implicar em erros sistemáticos (vieses). Tais constatações não podem ser desprezadas pelo Direito, cujo estudo deve empregar tal conhecimento interdisciplinar em sua análise das instituições jurídicas.

Abordando especificamente a possibilidade de ocorrência do viés de confirmação no processo penal, verificou-se como a participação de um mesmo julgador tanto na fase de investigação, com análise e deferimento de medidas cautelares, como na audiência de instrução em julgamento, com acessão aos autos do inquérito e ampla possibilidade de iniciativa probatória, pode ser perniciosa e implicar em uma tendência de confirmar decisões já proferidas em desfavor ou em favor do réu.

O processo penal brasileiro, nos moldes atuais, após a suspensão, pelo Supremo Tribunal Federal dos dispositivos legais que inauguraram o instituto do juiz de garantias, ignora a possibilidade de ocorrência de viés de confirmação pelos juízes. Com isso, contudo, não se está afirmando que os juízes criminais brasileiros tenham uma tendência que favoreça a acusação, mas há grande possibilidade de serem proferidas decisões condenatórias enviesadas em casos concretos, bem como a confirmação de absolvições indevidas.

Nesse contexto, pode-se dizer que o instituto do juiz de garantias é uma estratégia adequada para buscar evitar ou ao menos minimizar o viés de confirmação no processo penal, valorizando-se, dessa forma, a imparcialidade do julgador e, por consequência, um julgamento mais justo.

\section{LEVANTAMENTO BIBLIOGRÁFICO}

ALEXY, Robert. Teoria dos Direitos Fundamentais. Tradução de Virgílio Afonso da Silva. São Paulo: Malheiros, 2008.

BRASIL, Supremo Tribunal Federal, Ação Direta de Inconstitucionalidade n. 6.299 MC/DF, Relator Ministro Luiz Fux, julgado em 22/01/2020, publicado no Diário de Justiça Eletrônico n. 19 em 03/02/2020.

COSTA, Eduardo José da Fonseca. Juiz de Garantias e Viés de Confirmação. Empório do 
Direito, 2020. Disponível em https://emporiododireito.com.br/leitura/54-juiz-de-garantias-evies-de-confirmacao, acesso em 15 de junho de 2020.

COSTA, Eduardo José da Fonseca. Levando a Imparcialidade a Sério: proposta de um modelo interseccional entre direito processual, economia e psicologia. Tese de Doutorado em Direito Processual Civil - Pontifícia Universidade Católica de São Paulo. São Paulo. 187f. 2016.

FINDLEY, Keith A.; SCOTT, Michael S. Multiple Dimensions of Tunnel Vision in Criminal Cases, Wisconsin Law Review, p. 291, 2006.

GLOECKNER, Ricardo Jacobsen. Prisões cautelares, confirmation bias e o direito fundamental à devida cognição no processo penal. Revista Brasileira de Ciências Criminais, n. 117, p. 263-286, 2015.

HAIDT, Jonathan. Moral Psychology and the Law: how intuitions drive reasoning, judgment, and the search for evidence. Alabama Law Review. Vol. 64, 2013, p. 873.

HORTA, Ricardo Lins. Por que existem vieses cognitivos na Tomada de Decisão Judicial? A contribuição da Psicologia e das Neurociências para o debate jurídico. Revista Brasileira de Políticas Públicas, Brasília, v. 9, n. 3, p.83-122, 2019.

KAHNEMAN, Daniel. Rápido e Devagar: duas formas de pensar; Rio de Janeiro: Objetiva, 2012.

LIMA, Renato Brasileiro de. Manual de Processo Penal. Salvador: Editora Juspodivm, $8^{\text {a }}$ Edição, 2020.

LORD, C. G., ROSS, L., \& LEPPER, M. R. (1979). Biased assimilation and attitude polarization: The effects of prior theories on subsequently considered evidence. Journal of Personality and Social Psychology, 37, 2098-2109.

MERCIER, Hugo. Confirmation Bias - Myside Bias. In: POHL, Rüdiger F. (org.). Cognitive Illusions: Intriguing phenomena in thinking, judgment and memory. Nova Iorque: Routledge, $2^{\text {a }}$ Edição, 2017.

MAYA, André Machado. Juiz de Garantias: fundamentos, origem e análise da Lei 13.964/19. São Paulo: Tirant lo Blanch, 2020.

MYERS, David G. Psicologia Social. Porto Alegre: AMGH, 10ª Edição, 2014.

NOJIRI, Sergio. Emoção e intuição: como (de fato) se dá o processo de tomada de decisão judicial. Belo Horizonte: Arraes Editores, 2021.

NORTH, Douglass. Institutions, Institutional Change and Economic Performance. 
Cambridge University Press: Cambridge. 1990.

NICKERSON. Confirmation Bias: A ubiquitous phenomenon in many guises. Review of General Psychology, Vol. 2, No. 2, p. 175-220, 1998.

OLIVEIRA, Hélio Roberto Cabral de. Sobre A Inauguração Do Instituto Do Juiz De Garantias No Processo Penal Brasileiro: transplante jurídico acrítico ou tradução legal adequada ao ordenamento jurídico pátrio? In: II ENCONTRO VIRTUAL DO CONPEDI, 2020, Florianópolis. Direito penal, processo penal e constituição II. Florianópolis: CONPEDI, 2020. p. 8-24.

OSWALD, Margit E. e GROSJEAN, Stefan. Confirmation Bias. In Rüdiger F. Pohl (Org.). Cognitive Illusions: a handbook on fallacies and bias in thinking, judgment and memory. Nova Iorque: Psychology Press, 2005.

RICHARD, Thaler. Misbehaving: The Making of Behavioral Economics. W. W. Norton \& Company: New York, 2015.

ROSA, Alexandre Morais da. Guia do Processo Penal Conforme a Teoria dos Jogos. Florianópolis: EMais, 6 ${ }^{a}$ Edição, 2020, p. 344.

ROSA, Alexandre Morais; FELIX, Yuri. Novas tecnologias e a transformação cognitiva no processo penal. Boletim do Ibccrim, São Paulo, Ano 27, n. 322, setembro/2019, p. 6-7.

SCHÜNEMANN, Bernd. O juiz como um terceiro manipulado no processo penal? Uma confirmação empírica dos efeitos perseverança e correspondência comportamental. Revista Liberdades, $\quad \mathrm{n}^{\mathrm{o}} \quad 11 \quad$ - $\quad$ setembro/dezembro de 2012, disponível em http://www.revistaliberdades.org.br/site/outrasEdicoes/outrasEdicoesExibir.php?rcon_id=140. Acesso em 14 de junho de 2020.

SIMON, Herbert. A behavioral model of rational choice. Quarterly Journal of Economics. Vol. 69, n. 1, feb. 1955, p. 99-188. Disponível em https://www.suz.uzh.ch/dam/jcr:fffffffffad3-547b-ffff-fffff0bf4572/10.18-simon-55.pdf. Acesso em 14 de junho de 2020.

SUNSTEIN, Cass R.; JOLLS, Christine; THALER, Richard H. A Behavioral Approach to Law and Economics. Stanford Law Review, vol. 50, 1471, 1998.

SILVA, Larissa Marilia Serrano da. A construção do juiz das garantias no Brasil: a superação da tradição inquisitória. 2012. 118 f. Dissertação de Mestrado - Universidade Federal de Minas Gerais, Belo Horizonte, 2012.

SILVEIRA, Fabiano Augusto Martins. O código, as cautelares e o juiz de garantias. Revista de Informação Legislativa. Brasília, v. 46, n. 183, p. 77-93, jul./set./2009. 
WASON, P. C. On the failure to eliminate hypotheses in a conceptual task, Quarterly Journal of Experimental Psychology, 12:3, 129-140, 1960.

WOJCIECHOWSKI, Paola Bianchi; ROSA, Alexandre Morais da. Vieses da Justiça: como as heurísticas e vieses operam nas decisões penais e a atuação contraintuitiva. Florianópolis: EMais, 2a Edição, 2021.

ZAMIR, Eyal; TEICHMAN, Doron. The Oxford Handbook of Behavioral Economics and the Law. Oxford University Press: Oxford, 2014. 